\begin{tabular}{lc|c|c|}
\hline Bentham OPEN & The Open AIDS Journal \\
\hline CrossMark & Content list available at: www.benthamopen.com/TOAIDJ/ \\
\hline
\end{tabular}

\title{
A Review of HIV and Surgery in Africa
}

\author{
K. Bowa ${ }^{*}$, B. Kawimbe, D. Mugala, D. Musowoya, A. Makupe, M. Njobvu and C. Simutowe \\ The Copperbelt University School of Medicine, P.O Box. 71191, Ndola, Kitwe, Zambia
}

\begin{abstract}
HIV has a significant impact on surgery in Africa. Its' influence has spanned a period of about 30 years. In the 1980s' Africa experienced a rise in the national prevalence of HIV spreading across East Africa through Southern Africa, and reaching peak prevalence in the Southern African region. These prevalence levels have affected four key areas of surgical practice; namely patient care, practice of surgery, surgical pathologies, the practitioner and more recently prevention.

The surgical patient is more likely to be HIV positive in Africa, than elsewhere in the world. The patients are also more likely to have co infection with Hepatitis C or B and are unlikely to be aware of his or her HIV status. Surgical patients are also more likely to have impaired liver and renal function at the time of presentation. Therefore, HIV has affected the pattern of surgical pathologies, by influencing disease presentation, diagnosis, management and outcomes. It has also influenced the surgeon by increasing occupational risk and management of that risk. Recently in an ironic change of roles, surgery has impacted HIV prevention through the role of male circumcision as a significant tool in HIV prevention, which has traditionally focused on behavioural interventions.
\end{abstract}

The story of surgery and HIV continues to unfold on the continent. Ultimately presenting a challenge which requires innovation, dedication and hard work in the already resource limited environments of Africa.

Keywords: Africa, DCT, HIV, HPV, Male circumcision, Occupational Risk, Surgery.

\section{INTRODUCTION}

HIV prevalence in sub-Saharan Africa is one of the highest in the world. The epidemic began in East Africa in the 1980s, spreading through South Central Africa through the 1990s [1 - 3]. There are today an estimated 40 million people living with HIV infection, with over 25 million of these in sub-Saharan Africa. Well over $72 \%$ of deaths from HIV are in Africa [1 - 4]. On average one out of every ten adults in sub-Saharan Africa is HIV positive. The pandemic has had a significant effect on surgical practice in Africa. Among several areas in surgery, HIV has affected the surgical practitioner, the surgical patient, surgical pathologies, and the practice of surgery while surgery in turn has more recently influenced prevention strategies in $\operatorname{HIV}[5,6]$.

\section{The Patient}

The prevalence of HIV among surgical patients in sub-Saharan African is higher than that in the general population. It ranges from $32-39 \%$ in surgical patients in contrast to $11 \%$ in the general population in Malawi [7]. In South Africa, the prevalence of HIV among surgical patients was reported as $39 \%$ in contrast to the national prevalence of $22.4 \%$ [8].

The levels of HIV testing have remained relatively low in most African countries between 10-12\%. Most surgical patients do not know their HIV status [7, 8]. This has resulted in low access to care and treatment in many African countries. The World Health Organisation (WHO) introduced Diagnostic Counselling and Testing (DCT) or Provider Initiated Testing and Counselling (PICT) in 2007 to increase the uptake of care and treatment. DCT is testing at every point of access to the health services. The uptake of this method of HIV testing has been varied. However, it has meant increased levels of testing among surgical patients using an "opt out" approach. More patients requiring major surgery are now tested prior to surgery in many African countries. Though DCT has resulted in an increase in the level of

\footnotetext{
* Address correspondence to this author at the Copperbelt University School of Medicine, P.O Box. 71191, Ndola, Kitwe, Zambia; E-mail: kbowa@yahoo.com
} 
testing it has not necessarily resulted in improvement in care and treatment. Many patients presenting to the surgeon are already in the late stages of the disease at the time of DCT [7 - 9].

Among surgical admissions there is a larger proportion of female to male patients $(4: 1)$ and there is also a higher prevalence of HIV among females compared to males (46\% compared to $36 \%$ ). The age range of females in a South African study was reported as between 18 to 34 , with the age range in men being a decade later [7, 8]. When stratified by CD4 status most patients present to the surgical wards with CD4 counts below 500 cells $/ \mathrm{mm}^{3}$.

There is a high level of Hepatitis B and Hepatitis C co-infection of about 3 to $10 \%$ [10, 11]. Many low resourced countries do not routinely check for viral hepatitis co-infection. Recently with the increase in HAART treatment up to $10 \%$ of HIV patients are on HAART, and with the recent change in the WHO protocol more patients are likely to go on to HAART drugs [9 - 11].

\section{The Pathology}

With the advent of HIV there has been a change in the nature of surgical pathologies seen in Africa. The pathogenesis of HIV in Africa is mostly by heterosexual transmission, this represents $85 \%$ of the mode of transmission [12]. The transmission has been facilitated, by a high level of STI prevalence ranging from $8-10 \%$. Ulcerative STIs have been fuelled by a low level of male circumcision prevalence in most of sub-Saharan Africa, particularly in South Central Africa of $15-20 \%$ [13]. The normal low transmission of HIV of less than $0.01 \%$ has been augmented by these circumstances to as high as $0.3 \%$. This has increased the incidence of HIV among the youths of Africa in the age range of 17 to 35years [14], especially among women, in whom the wide mucosal surface increases significantly the rate of HIV transmission in comparison to men [15]. When the HIV virus enters the body, it binds to CD4 receptors found on defences cells. Then after the virus is internalised it begins to replicate. Preferentially it invades lymphocytes, and particularly the CD4 type Lymphocytes [16, 17]. This leads to a depletion of CD4 cells, which when they fall to below $200 / \mathrm{ml}$ results in a loss of body surveillance systems for malignancies and opportunistic infections. Among these opportunistic infections are mucosal viruses such as Human Papilloma Virus which also promote transformation of epithelial mucosal cells leading to increasing dysplasia and malignancy. Therefore HIV has promoted the development of multiple mucosal malignancies in Africa [17, 18] (Fig. 1).

The results are that these patients are susceptible to opportunistic infections, the most prevalent of which has been tuberculosis. In surgical practice, in particular, extra pulmonary tuberculosis has increased over the last 30 years since the advent of HIV, resulting in TB of the spine, joints, abdomen, lymph glands, pericardium, TB empyema, kidneys, testis and intracranial TB abscesses [19, 20].

The decline in T4 lymphocytes leads to a failure of cellular immunity which increases the virulence of commensal organisms in the immune incompetent host. This has led to an increase in infective and inflammatory condition in surgical patients, including multifocal abscesses, Fournier's gangrene, vasculitis, aneurysms, septic arthritis, prostatitis and cystitis $[21,22]$.

The loss of body surveillance for malignancies mediated by a vigilant immune system, has led to oncogenesis by mucosal virus such as HPV (human papilloma virus) and HHSV8 (human herpes virus 8). Prominent among mucosal cancers that have become common in Africa are; cancer of the eye, larynx, cervix, penis, anus, lymphomas and Kaposi's sarcoma [23, 24].

The virus is known to cause renal pathology such as HIVAN (HIV associated nephropathy) and many patients seen in surgical wards in Africa will therefore have renal impairment at the time of admission [25] .

\section{The Practice of Surgery}

The advent of HIV has influenced surgical practice across the continent. This has been seen in three main areas (Fig. 2), namely:

1. Diagnosis

2. Management

3. Outcomes 


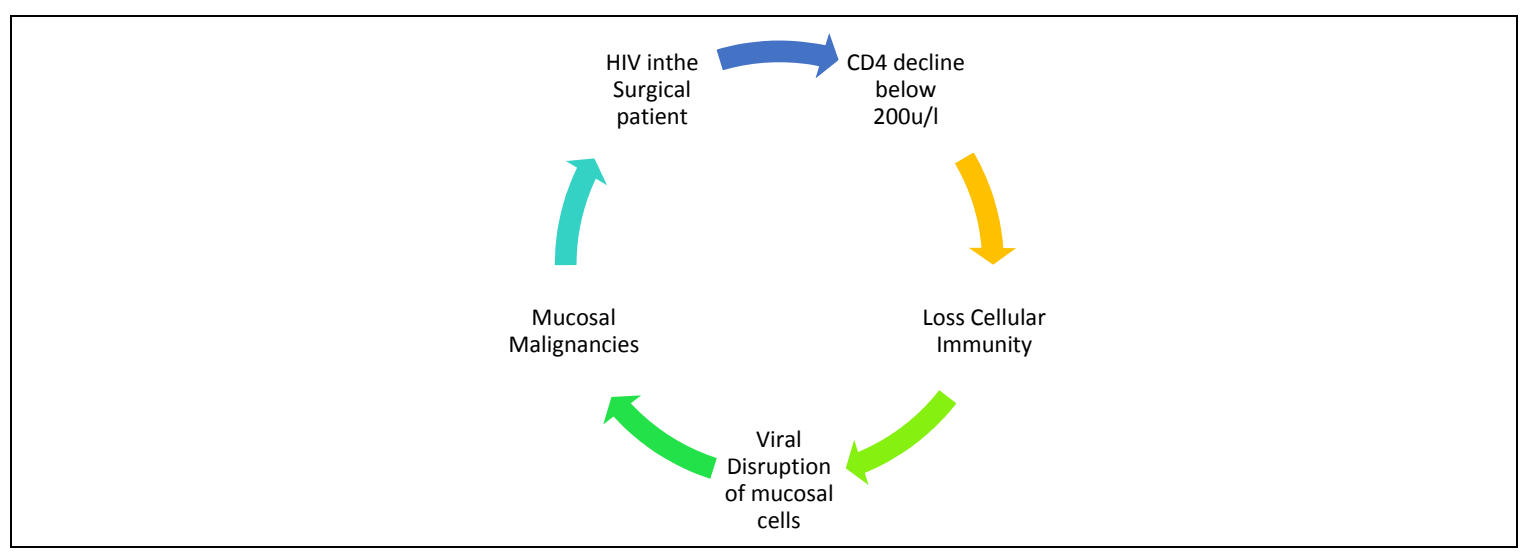

Fig. (1). The pathophysiology of increased mucosal malignancies in HIV positive surgical patients.

Whereas in the earlier years of the epidemic before the advent of HAART, HIV was largely seen as being within the domain of the Internal Medicine speciality, this view has changed with the patients living longer and presenting sometimes first with surgical pathologies. In response to this development, surgical practice has changed to meet this emerging challenge $[26,27]$.

HIV infection has changed surgical practice by altering the presentation of surgical diseases. This has created challenges in the early diagnosis of diseases and has seen uncommon diseases being seen commonly, or common diseases presenting in uncommon ways. This was especially so in the era before HAART treatment was commonly available.

Some very indolent diseases have been re-invigorated to present in very aggressive fashions. Infective and inflammatory conditions have also increased. Of particular note has been an increase in surgical sepsis arising from infective foci in the female genital tract, the pleura, the large joints and the anorectal area. Other surgical complications include pyomyositis, deep seated abscesses and perianal inflammatory pathologies.

In a study done in Zambia up to $44 \%$ of patients with gynaecological diseases were HIV positive [28]. Vascular diseases like aneurysms and peripheral vascular disease have also seen an upsurge in the surgeon's practice [29]. In the surgical subspecialties there has been a number of pathologies such as cytomegalovirus (CMV) cystitis, CMV retinitis, HPV papillomas of the larynx, nasopharyngeal carcinoma, osteomyelitis, cancers of the cervix and anus and Fournier's gangrene [29 - 31].

In the early days of the epidemic, the surgeon faced many challenges in the insertion of implants especially in fields like orthopaedics. Many patients in stages 3 and 4 of HIV disease had rejected metal implants for internal fixation of fractures. Subsequently the response to prosthesis has been better with the advent of HAART treatment.

Organ transplantation is uncommon in Africa, but the general policy has been to avoid organ transplant in patients who are HIV positive.

In patients with HIV associated malignancies such as Kaposi's Sarcoma, initial treatment focused on anticancer drugs with very high mortalities resulting. However with the advent of HAART the role of oncological drugs in the treatment of KS has been reversed. The treatment of HIV related sepsis by intensive care with multiple antibiotics has been overtaken by earlier treatment with HAART and restoration of better immune function [30 - 33].

For post operative patients, initial experience was of an increase in post-operative morbidity and high prevalence of surgical site infection (SSI). However with an overall improvement in medical management SSI infection prevalence among HIV patients has been shown to be similar to seronegative patients.

The management of HIV patient in emergency settings particularly in trauma has posed a special challenge. Many patients are undiagnosed and have to receive surgical care in an emergency setting without the prior advantage of HAART treatment. Studies have shown, that now, with stabilisation of the HIV pandemic the emergency care outcome has not differed significantly between the two groups [34 - 36]. 


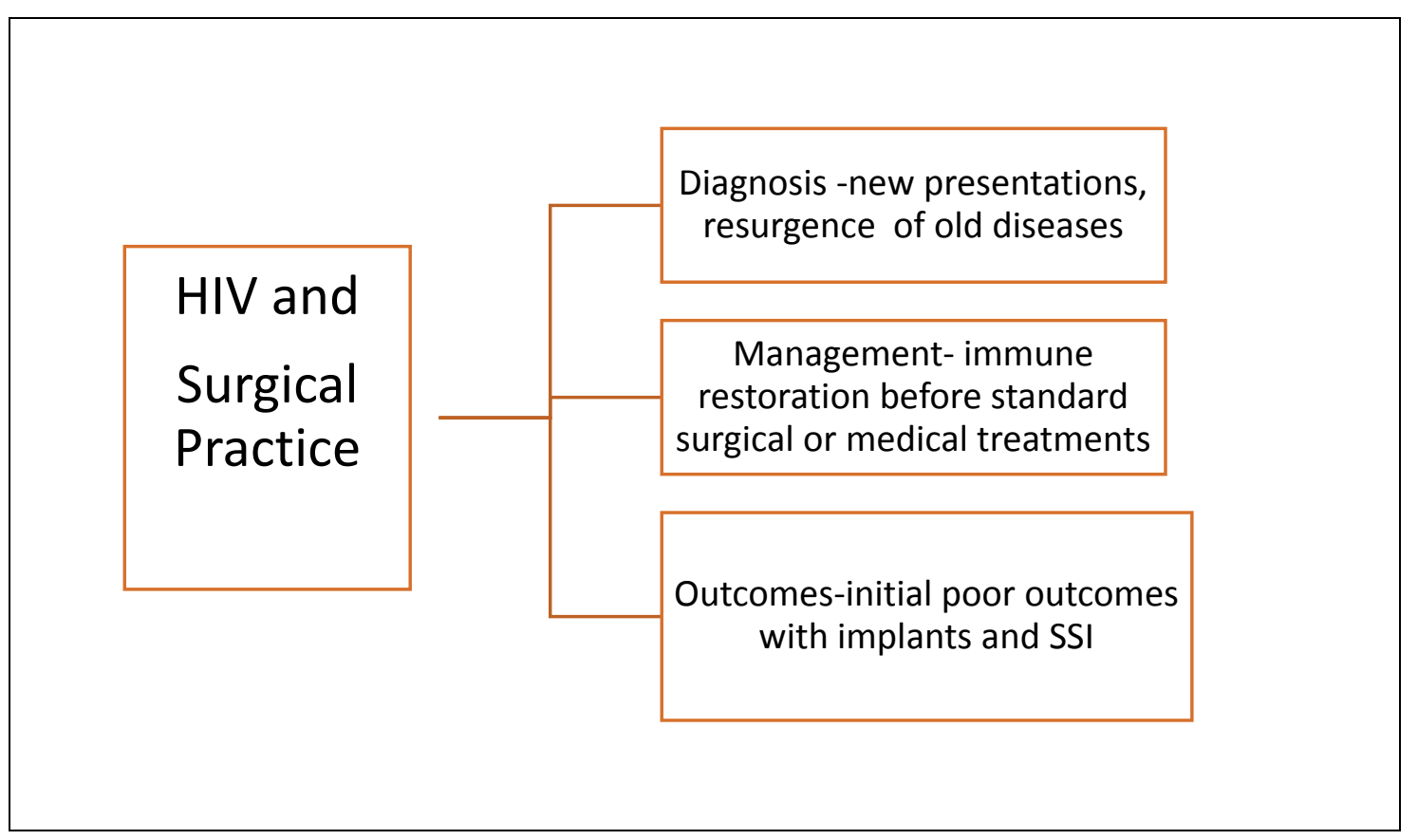

Fig. (2). The effects of HIV on surgical practice in Africa.

\section{The Practitioner}

With the increased burden of surgical disease which has come with HIV infection, there has been an increased pressure on surgical services. This has placed stress on an already overstretched surgical work force. There has been an attempt to innovatively address this challenge by a number of strategies including task shifting, task sharing and increased training of surgical specialists [37 - 39].

Many Surgeons and health workers practicing surgery in Africa have been affected by HIV. This is because there is a high prevalence of HIV in the population they work with and consequently there is a high HIV prevalence among patients seeking surgical services. In studies done in Africa the prevalence of HIV in surgical patients was found to range between $15-40 \%$. The WHO places the occupational risk of HIV at $0.3 \%$, this is significantly higher in Africa [40].

According to a report from Zambia, comparing the risk of HIV acquisition among surgeons in developed countries to those in developing countries, surgeons practicing in Africa have a 15 fold increased occupation risk of HIV. The study showed that the risk in Europe was $0.1 \%$ over 5 years while that in Zambia 1.5\% [41, 42]. Other studies in Africa attest to this increased risk both because of the high HIV prevalence, poor adherence to universal precautions due to resource limitation and relatively lower levels of safer surgical practices such as endoscopic /laparoscopy surgery.

These risks would be greatly reduced by the use of closed or less invasive surgical interventions [43]. In Tanzania the study showed an annual risk of $0.27 \%$ for all health workers and a $0.7 \%$ risk for surgeons. Another study In South Africa study showed an increased risk of splashing of blood in the eyes due to reluctance of surgeons to wear eye protection glasses $[43,44]$

The uptake of post exposure prophylaxis (PEP) after occupational exposure is also low among health care workers(HCW) in Africa, a study done in Kenyan, showed this to be $4 \%$ compared to $88 \%$ for hepatitis B. This is because HCW works are reluctant to undergo HIV testing, which is required before PEP can be administered [45].

\section{Surgery and HIV Prevention}

It is ironic that surgical practice in Africa which has been so heavily affected by HIV, should itself provide one of the potential prevention strategies. Therefore in discussing the effect of HIV on surgery in Africa, it would not be complete without a discussion on the effect of surgery on the HIV pandemic in Africa. 
In 2001, almost 20 years after the HIV pandemic hit Africa, the WHO added male circumcision as an additional HIV prevention strategy. This was based on 3 randomised control studies all done in Africa which showed that male circumcision, could reduce the risk of HIV acquisition by as much as $60 \%$ [46]

These studies done in a population of just over 10,000 men aged between 15 and 49, showed the preventive efficacy of male circumcision to range between 51\% to 64\%. In March 2007 WHO/UNAIDS issued recommendations that male circumcision was an efficacious HIV prevention strategy and should be rolled out in those high HIV prevalence and low male circumcision prevalence countries with a generalized epidemic and a heterosexual transmission pattern [47, 48], (Fig. 3)

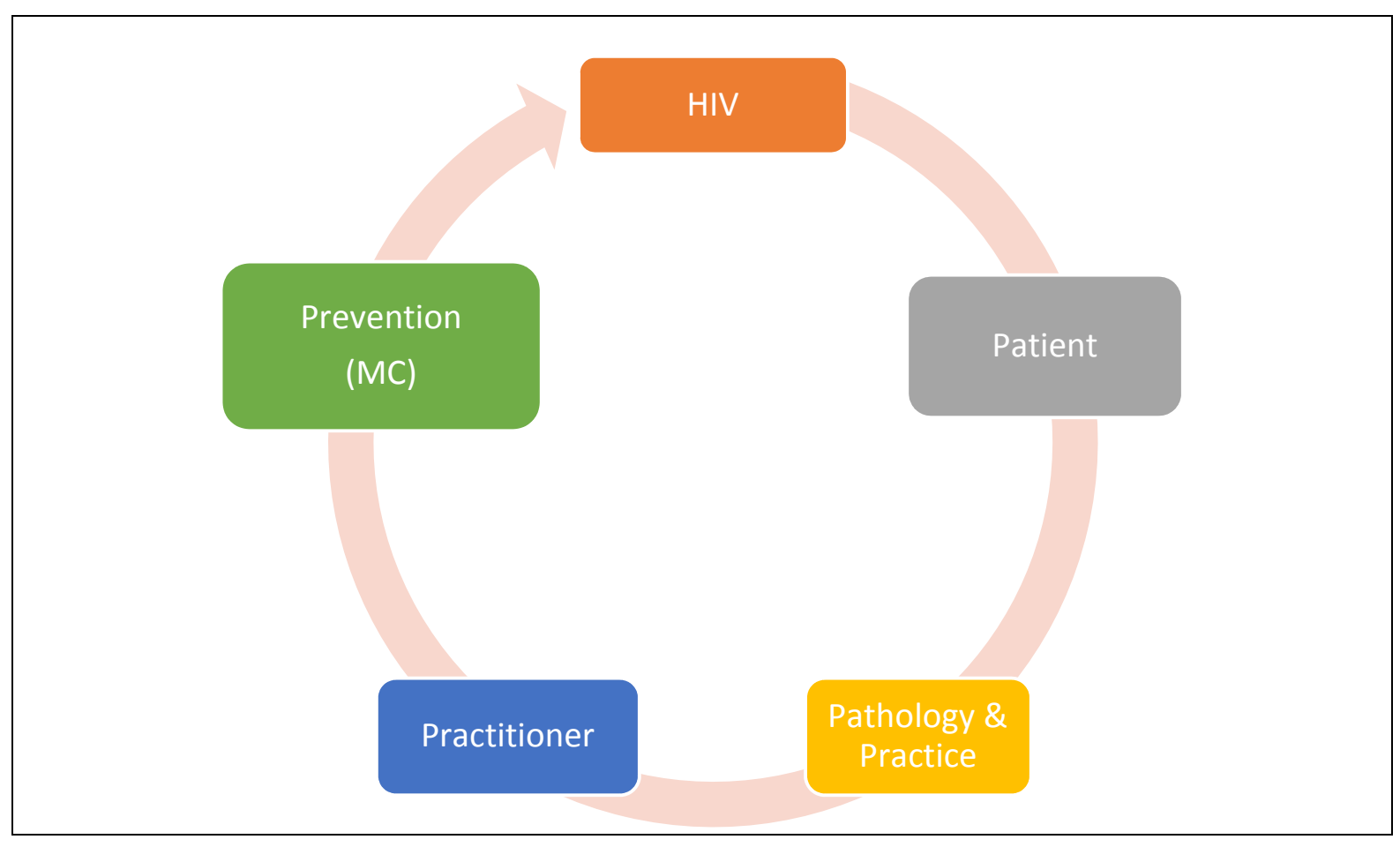

Fig. (3). The cycle of the effect of HIV on surgery and in turn the effect of surgery on HIV.

\section{CONCLUSION}

Africa has been the continent most severely affected by the HIV pandemic over the last 30 years. It has also been the setting of one of the most poorly resourced health services in the world. The surgical patient, pathology and practice have been heavily impacted by the HIV pandemic. There has been an increase in the volume of surgical patients who present primarily with surgical pathologies as a result of HIV infection. In addition many HIV patients present first to surgical services with their HIV status unknown. The prevalence of HIV among surgical patients ranges from $30 \%$ to $40 \%$ whilst there is a high incidence of co-infection with Hepatitis B and C. Surgical patients are typically, young, largely female and have a low CD4 count.

The surgical pathologies seen are of infections, inflammations and malignancies in various body systems. In particular there has been a notable increase in deep seated abscesses in unusual sites such as the chest cavity, the brain, the pelvis and the perineum. Surgical forms of extra pulmonary tuberculosis have emerged such as TB of the spine, kidney, abdomen and testis.

Other opportunistic infections such as cytomegalovirus(CMV) have been associated with retinitis and cystitis. Mucosal cancers have increased remarkably under the influence of human papilloma virus. These include cancer of the penis, anus, larynx and cervix. Other viruses such as Herpes 8 virus have been associated with Kaposi's sarcoma, a new variant of the old indolent $\mathrm{KS}$ disease.

These pathologies have affected specialised surgical treatments such as insertion of prosthesis, implants and organ transplantation. In spite of earlier fears that HIV would affect surgical outcomes, it has become clear that with HAART treatment, there is no significant difference. 
The high HIV prevalence of surgical patients has increased the occupational risk of practitioners up to 15 fold. In an environment of limited human resources this has added to the pressure placed on surgical services in Africa. Some innovations using minimally invasive techniques in managing surgical patients have emerged as a result of this.

The increased levels of HAART treatment have helped to ameliorate some of the surgical diseases of HIV infection. In this environment has come an additional surgical intervention in the prevention of HIV transmission, which builds on existing interventions. Male circumcision as an intervention has the potential to reduce HIV incidence in Africa by $37 \%$. Though challenges remain in its implementation, it presents an area of promise in HIV prevention.

\section{CONFLICT OF INTEREST}

The authors confirm that this article content has no conflict of interest.

\section{ACKNOWLEDGEMENTS}

Decleared None.

\section{REFERENCES}

[1] WHO annual report Global HIV/AIDS overview. Geneva, Switzerland: WHO 2005.

[2] Loefler IJ. The HIV pandemic and surgery. East Afr Med J 2001; 78(8): 393-4. [http://dx.doi.org/10.4314/eamj.v78i8.8986] [PMID: 11921557]

[3] Ronald AR, Ndinya-Achola JO, Plummer FA, et al. A review of HIV-1 in Africa. Bull N Y Acad Med 1988; 64(6): 480-90. [PMID: 3069166]

[4] Inungu J, Karl S. Understanding the scourge of HIV/AIDS in sub-Saharan Africa. MedGenMed 2006; 8(4): 30. [PMID: 17415312]

[5] Nyindo M. Complementary factors contributing to the rapid spread of HIV-I in sub-Saharan Africa: a review. East Afr Med J 2005; 82(1): 40-6.

[http://dx.doi.org/10.4314/eamj.v82i1.9293] [PMID: 16122111]

[6] Wamai RG, Morris BJ, Bailis SA, et al. Male circumcision for HIV prevention: current evidence and implementation in sub-Saharan Africa. J Int AIDS Soc 2011; 14: 49. [http://dx.doi.org/10.1186/1758-2652-14-49] [PMID: 22014096]

[7] Haac BE, Charles AG, Matoga M, LaCourse SM, Nonsa D, Hosseinipour M. HIV testing and epidemiology in a hospital-based surgical cohort in Malawi. World J Surg 2013; 37(9): 2122-8. [http://dx.doi.org/10.1007/s00268-013-2096-4] [PMID: 23652356]

[8] Cacala SR, Mafana E, Thomson SR, et al. Prevalence of HIV status and CD4 counts in a surgical cohort: their relationship to clinical outcome. Ann R Coll Surg Eng 2006; 88(1): 46-51.

[9] Guidance on provider initiated HIV testing and counselling in Health facilities. Geneva, Switzerland: WHO 2007.

[10] Wondimeneh Y, Alem M, Asfaw F, Belyhun Y. HBV and HCV seroprevalence and their correlation with CD4 cells and liver enzymes among HIV positive individuals at University of Gondar Teaching Hospital, Northwest Ethiopia. Virol J 2013; $10(171)$ : 171. [http://dx.doi.org/10.1186/1743-422X-10-171] [PMID: 23721493]

[11] Kapembwa KC, Goldman JD, Lakhi S, et al. HIV, Hepatitis B, and Hepatitis C in Zambia. J Glob Infect Dis 2011; 3(3): 269-74. [http://dx.doi.org/10.4103/0974-777X.83534] [PMID: 21887060]

[12] Bayley AC. Surgical pathology of HIV infection: lessons from Africa. Br J Surg 1990; 77(8): 863-8. [http://dx.doi.org/10.1002/bjs.1800770806] [PMID: 2203506]

[13] Hunter DJ. AIDS in sub-Saharan Africa: the epidemiology of heterosexual transmission and the prospects for prevention. Epidemiology 1993; 4(1): 63-72.

[http://dx.doi.org/10.1097/00001648-199301000-00012] [PMID: 8420583]

[14] Stanley MA, Winder DM, Sterling JC, Goon PK. HPV infection, anal intra-epithelial neoplasia (AIN) and anal cancer: current issues. BMC Cancer 2012; 12: 398 . [http://dx.doi.org/10.1186/1471-2407-12-398] [PMID: 22958276]

[15] Naidoo NG, Beningfield SJ. Other manifestations of HIV vasculopathy. S Afr J Surg 2009; 47(2): 46-53. [PMID: 19626780]

[16] Jellis JE. Orthopaedic surgery and HIV disease in Africa. Int Orthop 1996; 20(4): 253-6. [http://dx.doi.org/10.1007/s002640050074] [PMID: 8872550]

[17] Islam J, Clarke DL, Thomson SR. Lessons from emergency laparotomy for abdominal tuberculosis in the HIV/AIDS era. S Afr J Surg 2014; 52(1): 10-2.

[PMID: 24881132] 
[18] Bowa K, Labib M. A review of HIV in Urology. Zambia Med J 2003; 5(2): 77-9.

[19] Silumbe M, Labib M, Bowa K. A review of HIV in Urology. Uro Today Int J 2013; 6(1) 6. [http://dx.doi.org/10.3834/uij.1944-5784.2013.02.06]

[20] Dua RS, Wajed SA, Winslet MC. Impact of HIV and AIDS on surgical practice. Ann R Coll Surg Engl 2007; 89(4): 354-8. [http://dx.doi.org/10.1308/003588407X183436] [PMID: 17535610]

[21] Bowa K, Malyangu E, Wood C, Angelleti P. A pilot study to compare HIV status and cervical and penile pathology among couples attending the urology unit at UTH. Zambia Med J 2010; 27(2): 84-8.

[22] Kapatamoyo B, Andrews B, Bowa K. Association of HIV with breast abscess and altered microbial susceptibility. Med J Zambia 2010; 37(2): 58-63.

[PMID: 23170038]

[23] Bowa K, Kachimba JS, Labib M, Mudenda V, Chikwenya M. The changing pattern of Urological Cancers in Zambia. Med J Zambia 2009; 35(4): 157-9.

[24] Bowa K, Wood C, Chao A, Chintu C, Mudenda V, Chikwenya M. The epidemiology of cancers at Lusaka University Teaching Hospital in Zambia. East and Central Africa J of Sur 2008; 13(2): 125-32.

[25] Kalyesubula R, Wearne N, Semitala FC, Bowa K. HIV-associated renal and genitourinary comorbidities in Africa. J Acquir Immune Defic Syndr 2014; 67(Suppl. 1): S68-78.

[http://dx.doi.org/10.1097/QAI.0000000000000259] [PMID: 25117962]

[26] Loefler I. The contest between a clever virus and a facultatively clever host. J R Soc Med 2002; 95(10): 516-7. [http://dx.doi.org/10.1258/jrsm.95.10.516] [PMID: 12356980]

[27] Bayley AC. Surgical pathology of HIV infection: lessons from Africa. Br J Surg 1990; 77(8): 863-8. [http://dx.doi.org/10.1002/bjs.1800770806] [PMID: 2203506]

[28] Watters D A K. Severe peritoneal sepsis. In: Surgery in the tropics. London, United Kingdom: Bailliere Tindall 1988; 3: pp. 275-300.

[29] Jellis JE. Orthopaedic surgery and HIV disease in Africa. Int Orthop 1996; 20(4): 253-6. [http://dx.doi.org/10.1007/s002640050074] [PMID: 8872550]

[30] Elem B, Ranjan P. Impact of immunodeficiency virus (HIV) on Fournier's gangrene: observations in Zambia. Ann R Coll Surg Engl 1995; 77(4): 283-6. [PMID: 7574321]

[31] Patil P, Elem B, Zumla A. Pattern of adult malignancies in Zambia (1980-1989) in light of the human immunodeficiency virus type 1 epidemic. J Trop Med Hyg 1995; 98(4): 281-4. [PMID: 7636927]

[32] Elem B, Patil PS. Renal tuberculosis in Zambia: observation on 900 consecutive autopsies. Med J Zambia 1984; $18(1)$ : 5-7. [PMID: 6534035]

[33] Aird J, Noor S, Lavy C, Rollinson P. The effect of HIV on early wound healing in open fractures treated with internal and external fixation. J Bone Joint Surg Br 2011; 93(5): 678-83. [http://dx.doi.org/10.1302/0301-620X.93B5.26081] [PMID: 21511935]

[34] Saltzman DJ, Williams RA, Gelfand DV, Wilson SE. The surgeon and AIDS: twenty years later. Arch Surg 2005; $140(10)$ : 961-7. [http://dx.doi.org/10.1001/archsurg.140.10.961] [PMID: 16230546]

[35] Cacala SR, Mafana E, Thomson SR, Smith A. Prevalence of HIV status and CD4 counts in a surgical cohort: their relationship to clinical outcome. Ann R Coll Surg Engl 2006; 88(1): 46-51.

[http://dx.doi.org/10.1308/003588406X83050] [PMID: 16460640]

[36] Crabtree KL, Wojcicki JM, Minhas V, et al. Risk factors for early childhood infection of human herpesvirus-8 in Zambian children: the role of early childhood feeding practices. Cancer Epidemiol Biomarkers Prev 2014; 23(2): 300-8. [http://dx.doi.org/10.1158/1055-9965.EPI-13-0730] [PMID: 24296855]

[37] Lavy C, Tindall A, Steinlechner C, Mkandawire N, Chimangeni S. Surgery in Malawi - a national survey of activity in rural and urban hospitals. Ann R Coll Surg Eng1 2007; 89(7): 722-4. [http://dx.doi.org/10.1308/003588407X209329] [PMID: 17959015]

[38] Mkandawire N, Ngulube C, Lavy C. Orthopaedic clinical officer program in Malawi: a model for providing orthopaedic care. Clin Orthop Relat Res 2008; 466(10): 2385-91. [http://dx.doi.org/10.1007/s11999-008-0366-5] [PMID: 18633684]

[39] Chalya PL, Ssentongo R, Kakande I. HIV seroprevalence and its effect on outcome of moderate to severe burn injuries: A Ugandan experience. J Trauma Manag Outcomes 2011; 5(1): 8. [http://dx.doi.org/10.1186/1752-2897-5-8] [PMID: 21658212]

[40] Anon. Guidelines on Post Exposure Prophylaxis for HIV Recommendations for a Public Health Approach. Geneva: World Health Organization 2014.

[41] Consten EC, van Lanschot JJ, Henny PC, Tinnemans JG, van der Meer JT. A prospective study on the risk of exposure to HIV during surgery 
in Zambia. AIDS 1995; 9(6): 585-8.

[http://dx.doi.org/10.1097/00002030-199506000-00009] [PMID: 7662197]

[42] Gumodoka B, Favot I, Berege ZA, Dolmans WM. Occupational exposure to the risk of HIV infection among health care workers in Mwanza Region, United Republic of Tanzania. WHO Bull OMS 1997; 75(2): 133-40.

[43] Labib M. Scalpel-free surgery could reduce surgeons' risk of HIV and hepatitis. Med J Zambia 2010; 37(2): 99-103. [PMID: 23457420]

[44] Szabo CP, Dhai A, Veller M. HIV-positive status among surgeons - an ethical dilemma. SAfr Med J 2006; 96(10): 1072-5. [PMID: 17164938]

[45] Taegtmeyer M, Suckling RM, Nguku PM, et al. Working with risk: occupational safety issues among healthcare workers in Kenya. AIDS Care 2008; 20(3): 304-10

[http://dx.doi.org/10.1080/09540120701583787] [PMID: 18351477]

[46] Fink AJ. A possible explanation for heterosexual male infection with AIDS. N Engl J Med 1986; $315(18)$ : 1167. [http://dx.doi.org/10.1056/NEJM198610303151818] [PMID: 3762636]

[47] Bailey RC, Moses S, Parker CB, et al. Male circumcision for HIV prevention in young men in Kisumu, Kenya: a randomised controlled trial. Lancet 2007; 369(9562): 643-56.

[http://dx.doi.org/10.1016/S0140-6736(07)60312-2] [PMID: 17321310]

[48] Donoval BA, Landay AL, Moses S, et al. HIV-1 target cells in foreskins of African men with varying histories of sexually transmitted infections. Am J Clin Pathol 2006; 125(3): 386-91. [http://dx.doi.org/10.1309/JVHQVDJDYKM58EPH] [PMID: 16613341]

Received: February 27, 2015

Revised: July 9, 2015

Accepted: October 12, 2015

(C) Bowa et al.; Licensee Bentham Open.

This is an open access article licensed under the terms of the Creative Commons Attribution-Non-Commercial 4.0 International Public License (CC BY-NC 4.0) (https://creativecommons.org/licenses/by-nc/4.0/legalcode), which permits unrestricted, non-commercial use, distribution and reproduction in any medium, provided the work is properly cited. 